\title{
Genotype-independent association between profound vitamin D deficiency and delayed sputum smear conversion in pulmonary tuberculosis
}

Kashaf Junaid ${ }^{1,2^{*}}$, Abdul Rehman ${ }^{1}$, Tahir Saeed ${ }^{3}$, David A. Jolliffe ${ }^{2}$, Kristie Wood $^{4}$ and Adrian R. Martineau ${ }^{2}$

\begin{abstract}
Background: Both vitamin D deficiency and genetic variants in the vitamin D receptor (VDR) have been reported to associate with delayed response to intensive-phase therapy for pulmonary tuberculosis. Studies investigating the influence of genetic variants in vitamin D binding protein (DBP) and vitamin D 25-hydroxylase (CYP2R1) on vitamin D status and response to antituberculous therapy are lacking.

Methods: We conducted a longitudinal study in 260 patients initiating treatment for smear-positive pulmonary tuberculosis in Lahore, Pakistan. Vitamin D status and genotypes for polymorphisms in VDR (rs2228570, rs731236, rs1544410), DBP (rs7041, rs4588) and CYP2R1 (rs2060793, rs10500804, rs10766197) were determined at baseline. Sputum smear microscopy was performed at 2, 4, 6 and 8 weeks, and time to sputum smear conversion was estimated for each participant. Analyses were conducted to determine demographic, clinical and genetic determinants of baseline vitamin D status and time to sputum smear conversion.

Results: Profound vitamin D deficiency (serum 25[OH]D $<25 \mathrm{nmol} / \mathrm{L}$ ) was highly prevalent at TB diagnosis (present in $54 \%$ of patients), and was independently associated with female vs. male sex (adjusted OR 2.60, $95 \% \mathrm{Cl} 1.50$ to 4.52, $P=0.001$ ), recruitment in October to March inclusive (adjusted OR $1.75,95 \% \mathrm{Cl} 1.00$ to $3.04, P=0.047$ ) and bilateral vs. unilateral disease (adjusted OR $1.89,95 \% \mathrm{Cl} 1.49$ to $4.52 P=0.025$ ). Profound vitamin $\mathrm{D}$ deficiency was also independently associated with impaired response to antituberculous therapy (median time to sputum smear conversion 22.5 vs. 7.5 days for patients with serum 25[OH]D $<25 \mathrm{nmol} / \mathrm{L}$ vs. $\geq 25 \mathrm{nmol} / \mathrm{L}$, respectively; aHR 4.36, $95 \% \mathrm{Cl} 3.25$ to 6.65, P < 0.001). No polymorphisms in VDR, CYP2R1 and DBP studied associated with either baseline vitamin D status or time to sputum smear conversion.
\end{abstract}

Conclusions: Profound vitamin D deficiency is very common among TB patients in Lahore, Pakistan, and is independently associated with significantly delayed sputum smear conversion. Polymorphisms in VDR, CYP2R1 and DBP did not associate with baseline vitamin D status or response to intensive-phase treatment in this patient group.

Keywords: Tuberculosis, Vitamin D deficiency, Vitamin D receptor, CYP2R1, Vitamin D binding protein, Single nucleotide polymorphism

\footnotetext{
* Correspondence: kashaf_junaid@hotmail.com

'Department of Microbiology and Molecular Genetics, University of the Punjab, Quaid-e-Azam Campus, PO Box No 54590, Lahore 54000, Pakistan

${ }^{2}$ Centre for Primary Care and Public Health, Barts and The London School of Medicine and Dentistry, Queen Mary University of London, London E1 2AB, UK

Full list of author information is available at the end of the article
}

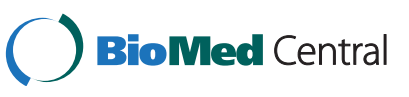

(c) 2015 Junaid et al. This is an Open Access article distributed under the terms of the Creative Commons Attribution License (http://creativecommons.org/licenses/by/4.0), which permits unrestricted use, distribution, and reproduction in any medium, provided the original work is properly credited. The Creative Commons Public Domain Dedication waiver (http:// creativecommons.org/publicdomain/zero/1.0/) applies to the data made available in this article, unless otherwise stated. 


\section{Background}

Despite widespread availability of antimicrobial therapy, tuberculosis continues to carry a significant case fatality rate, estimated at 4-7 \% in notified HIV-uninfected cases [1]. An improved understanding of the risk factors for poor response to antituberculous therapy could lead to the development of new interventions to improve treatment outcome.

A growing body of evidence suggests that vitamin D deficiency may be one such factor [2]. High-dose vitamin $\mathrm{D}$ was used to treat tuberculosis in the pre-antibiotic era, [3] and vitamin D metabolites support the induction of a broad range of antimycobacterial effector responses in vitro [4-8]. Vitamin D deficiency associates with impaired response to antituberculous therapy [9-11]. Genetic variants in the vitamin D receptor (VDR), which transduces vitamin D signal to modify transcriptional responses, have also been reported to predict treatment response [12, 13]. Polymorphisms in the vitamin D binding protein (DBP), which transports vitamin $\mathrm{D}$ metabolites in the circulation, and the vitamin D 25hydroxylase enzyme (CYP2R1), which converts 'parent' vitamin $\mathrm{D}$ to its major circulating metabolite 25hydroxyvitamin D (25[OH]D), influence vitamin D status in the general population [14]. However, their potential influence on vitamin $\mathrm{D}$ status and response to antimicrobial therapy in TB patients has not previously been studied. Moreover, despite evidence that effects of vitamin D status on the response to $M$. tuberculosis are genotype-dependent, [15-17] studies investigating the potential effect of interactions between vitamin $\mathrm{D}$ status and polymorphisms in the vitamin D pathway on response to antituberculous therapy have not previously been performed. We therefore conducted an observational study to determine a) the prevalence and determinants of vitamin D deficiency among a cohort of patients with newly-diagnosed pulmonary tuberculosis in Lahore, Pakistan; b) whether baseline vitamin D status and / or polymorphisms in VDR, DBP or CYP2R1 associated with response to intensive-phase antituberculous therapy in these patients as main effects, and c) whether any associations between vitamin $\mathrm{D}$ deficiency and response to treatment were genotype-dependent.

\section{Methods}

\section{Study population}

Patients attending Gulab Devi Chest Hospital, Lahore, Pakistan (Latitude $31.5^{\circ} \mathrm{N}$ ) for treatment of smearpositive pulmonary tuberculosis were screened for eligibility to participate in the study. The following were excluded: those aged less than 14 years or more than 60 years; those who had already initiated antituberculous therapy; those with a medical record diagnosis of type 1 or type 2 diabetes mellitus, chronic renal failure, hepatic failure or ischaemic heart disease; and those with serological evidence of Hepatitis B, Hepatitis C or HIV infection. Those fulfilling eligibility criteria completed a questionnaire detailing age, gender and socioeconomic status (as indicated by whether or not they were in receipt of financial aid for hospital costs). All participants had a chest radiograph at baseline, which was classified as showing either unilateral or bilateral disease by the consultant chest physician in charge of their care. Participants also gave a sputum sample (for microscopy $+/$ - mycobacterial culture as detailed below) and a $5 \mathrm{ml}$ blood sample at baseline. Half of this blood sample was drawn into a serum tube, and the half was drawn into an EDTA tube. Serum tubes were centrifuged, and serum was aspirated and stored at $-20{ }^{\circ} \mathrm{C}$ for subsequent assay of $25(\mathrm{OH}) \mathrm{D}$ concentration. Whole blood in EDTA was stored at $4{ }^{\circ} \mathrm{C}$ for subsequent DNA extraction. Participants whose baseline blood sample was haemolysed were excluded from analyses. Participants then initiated directly-observed antituberculous treatment according to WHO guidelines [18] and were followed up 2, 4, 6 and 8 weeks later. At each time point they were asked to provide a repeat sputum sample for microscopy, until either their sputum sample was smear-negative, or they were unable to expectorate. Data from patients who attended their final follow-up visit late were included up to 10 weeks from initiation of antimicrobial treatment. Medical staff caring for participants were informed of their patients' vitamin $\mathrm{D}$ status at the end of the study, and were free to manage this as they deemed appropriate after the participant had completed follow-up. The study was approved by the ethics committees of the School of Biological Sciences, University of Punjab (ref SBS 873-12) and of the Gulab Devi Chest Hospital, Lahore. All participants gave informed consent to take part.

\section{Laboratory methods}

Microscopy of Ziehl-Nielsen (ZN) -stained sputum samples was performed in the Microbiology Laboratory at the Gulab Devi Chest Hospital by trained staff using written standard operating procedures. These staff were blinded to participants' vitamin D status. Bacillary load in baseline sputum samples was classified according to the number of acid-fast bacilli seen per high power field (HPF). Mycobacterial culture and drug sensitivity testing was done for a sub-group of patients who fulfilled hospital criteria for performing this test, namely those who were sputum-smear positive after 2 weeks of intensivephase anti-TB treatment, and who had either been previously treated for tuberculosis or who were known to have had contact with patients with confirmed MDR-TB. Sputum samples from patients selected for drug sensitivity testing were initially assessed using the GeneXpert MTB/RIF platform [19]. Samples which were positive on 
this molecular test were then cultured on Lowenstein Jensen medium, and colonies were sent for phenotypic drug sensitivity testing using the Bactec MGIT system as described [20]. Serum 25(OH)D concentrations were determined by ELISA (Immunodiagnostic Systems, Boldon, $\mathrm{UK})$; the inter-assay coefficient of variation was $11.5 \%$, and the average duration of sample storage prior to $25(\mathrm{OH}) \mathrm{D}$ assay was 91.2 days. Profound vitamin D deficiency was defined as a serum $25(\mathrm{OH}) \mathrm{D}$ concentration $<25 \mathrm{nmol} / \mathrm{L}$. Genomic DNA was extracted from whole blood [21] and quantified using the Nanodrop spectrophotometer and normalised to $5 \mathrm{ng} / \mu \mathrm{l} .10 \mathrm{ng}$ DNA was used as template for $2 \mu \mathrm{l}$ TaqMan allelic discrimination assays (Applied Biosystems, Foster City, CA, USA) performed on the ABI 7900HT platform in 384-well format and analysed with Autocaller software, as previously described [22]. Pre-developed assays were used to type polymorphisms in genes encoding VDR (rs2228570 [FokI], rs731236 [TaqI] and rs1544410 [BsmI]), CYP2R1 (rs2060793, rs10500804 and rs10766197) and DBP (rs7041 [HaeIII] and rs4588 [StyI]). Genotyping assays failed in a small proportion of subjects, possibly as a result of poor DNA quality. Alleles at all loci conformed to the Hardy-Weinberg equilibrium.

\section{Sample size and statistical analyses}

The study was prospectively powered to estimate prevalence of profound vitamin D deficiency in the study population with a $5 \%$ error margin at the $95 \%$ confidence level, using published algorithms [23]. Assuming an expected frequency of $79 \%$, [24] we calculated that a total of $n=253$ participants would need to be recruited.

Statistical analyses were done with SPSS (version 20.0) and Stata IC (version 12) and figures were prepared with GraphPad Prism (version 4.00). The date of sputum smear conversion was estimated as the midpoint between the date of the last positive sputum smear and the date of the first negative sputum smear thereafter. Time to sputum smear conversion was calculated as the number of days from the date on which antituberculous treatment was initiated to the estimated date of sputum smear conversion.

Univariate analysis of associations between potential determinants of vitamin D status and risk of profound vitamin $\mathrm{D}$ deficiency was done using chi square tests; those found to associate with $P<0.1$ on univariate analysis were included in multivariate analysis, which was done with binary logistic regression. Analysis of determinants of time to sputum smear conversion was done using Cox regression. Sub-group analyses to test for gene-environment interactions were performed by Cox regression with the inclusion of interaction terms between genotype and vitamin D status
$(25[\mathrm{OH}] \mathrm{D}<25 \mathrm{nmol} / \mathrm{L}$ vs. $\geq 25 \mathrm{nmol} / \mathrm{L})$; for these analyses, the Benjamini-Hochberg procedure for multiple testing correction was applied to control the false discovery rate with a q value threshold of 0.2 [25]. For all analyses, the influence of potential genetic determinants on dependent variables was assessed using additive models. Interaction effects were summarised as a ratio of hazard ratios with $95 \%$ confidence interval and P-value. Statistical significance was assumed where $P<0.05$.

\section{Results}

\section{Participant enrolment and follow-up}

Three hundred patients with smear-positive pulmonary TB fulfilling study eligibility criteria were recruited to the study from the Gulab Devi Chest Hospital, Lahore, Pakistan between August 2012 and November 2013. Of these, 40 were excluded from the analysis, 26 due to sampling after the start of antituberculous treatment and 14 due to haemolysis of blood samples. Of the remaining 260 patients, 248 completed follow-up, 10 were lost to follow-up and 2 died (Fig. 1).

\section{Baseline characteristics of study participants}

The mean age of the 260 participants entering analysis was 31.6 years (standard deviation 10.5 years, range 14 to 55 years), and 140 (54\%) were female. One hundred and thirty seven patients (53\%) were enrolled in the sunnier part of the year (April to September inclusive), and $123(47 \%)$ were enrolled in the less sunny part of the year (October to March inclusive). One hundred and forty-four patients $(55 \%)$ had unilateral disease on chest radiograph, and 116 (45\%) had bilateral disease. Seventy-two patients $(28 \%)$ fulfilled hospital criteria for performing drug sensitivity testing, of whom 56 (78 \%) had fully-sensitive disease and 16 (22\%) had MDR TB. Vitamin D deficiency was highly prevalent at baseline: 140 patients $(54 \%)$ had serum $25(\mathrm{OH}) \mathrm{D}<25 \mathrm{nmol} / \mathrm{L}$, 97 (37 \%) had serum 25(OH)D 25-49.9 nmol/L, 17 (7\%) had serum 25(OH)D 50-74.9 nmol/L and only 6 (2\%) had serum $25(\mathrm{OH}) \mathrm{D} \geq 75 \mathrm{nmol} / \mathrm{L}$ (Table 1$)$. Median 25(OH)D concentration was $23.3 \mathrm{nmol} / \mathrm{L}$ (interquartile range 16.0 to $34.0 \mathrm{nmol} / \mathrm{L}$ ).

\section{Determinants of baseline vitamin $D$ status}

Phenotypic and genotypic determinants of baseline vitamin D status are presented in Table 2. Multivariate analysis revealed independent associations between profound vitamin $\mathrm{D}$ deficiency (serum $25[\mathrm{OH}] \mathrm{D}<25 \mathrm{nmol} / \mathrm{L}$ ) and female sex (aOR 2.60, $95 \%$ CI 1.50 to $4.52, P=0.001$ ); recruitment between October and March, inclusive (aOR $1.75,95 \%$ CI 1.00 to 3.04. $P=0.047$ ); and bilateral disease (aOR 1.89, $95 \%$ CI 1.49 to $4.52, P=0.025$; Fig. 2). No independent associations were observed between baseline vitamin $\mathrm{D}$ status and age, socio-economic status, degree 


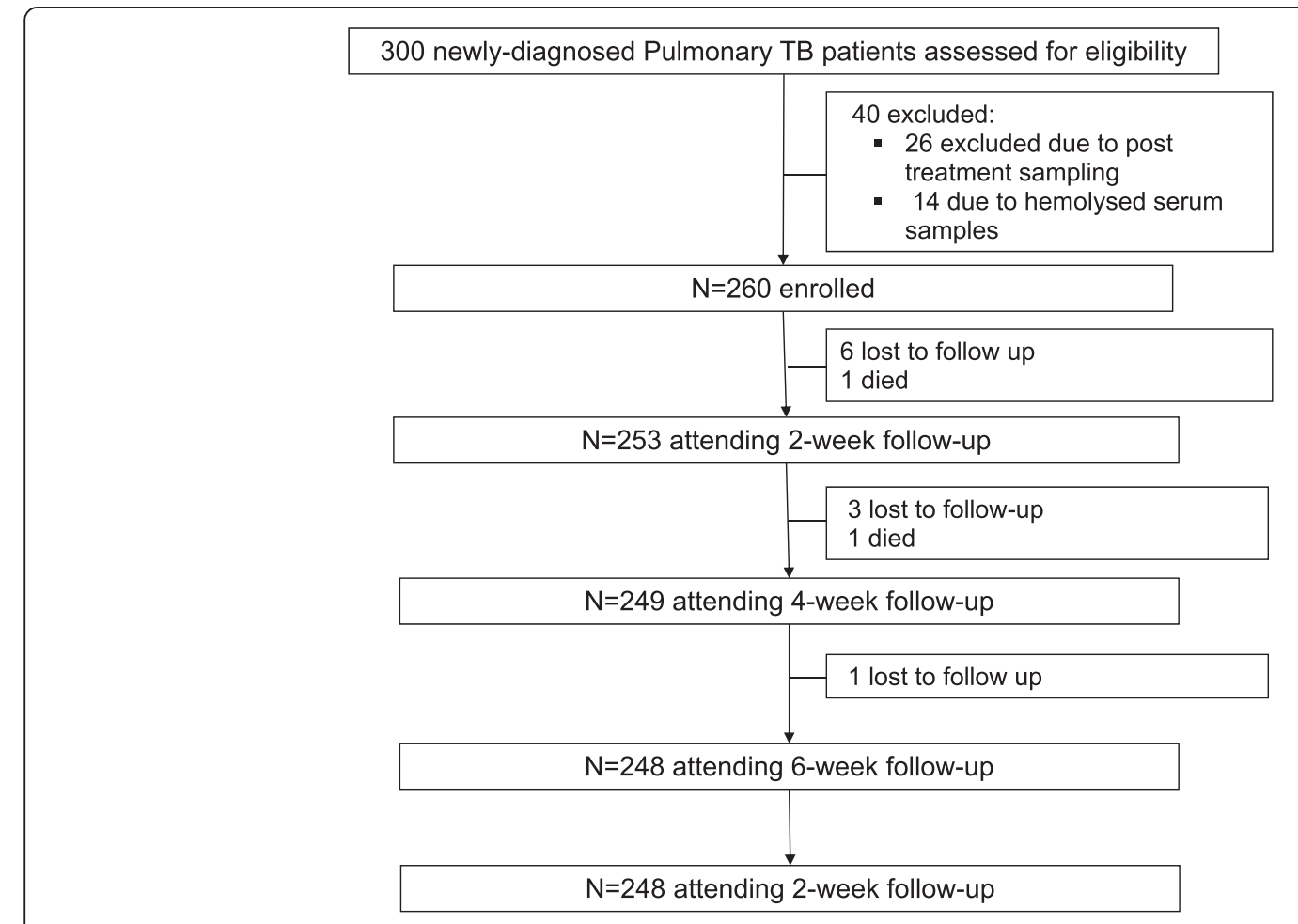

Fig. 1 Participant enrolment and follow-up

of smear-positivity at baseline or any polymorphism studied.

\section{Determinants of time to sputum smear conversion}

Phenotypic and genotypic determinants of time to sputum smear conversion are presented in Table 3. Multivariate analysis adjusting for sex, radiological extent of disease, baseline vitamin D status and drug sensitivity revealed independent associations between delayed sputum smear conversion and profound vitamin D deficiency at baseline (aHR 4.36, 95 \% CI 3.25 to $6.65, P<0.001)$. Isolation of a multidrug-resistant organism on sputum culture was also independently associated with delayed sputum smear conversion (aHR 3.35, $95 \%$ CI 1.71 to $6.54, P<0.001$ )(Fig. 3). No independent associations were observed between delayed sputum smear conversion and socio-economic status, radiographic extent of disease, age or any polymorphism investigated.

In order to investigate the possibility that the presence of undiagnosed MDR-TB may have confounded the relationship between low baseline vitamin $\mathrm{D}$ status and delayed sputum culture conversion, we repeated the multivariate Cox regression analysis of determinants of time to sputum smear conversion in the sub-group of 72 patients for whom DST results were available, adjusting for sex, radiological extent of disease, baseline vitamin D status and drug sensitivity as before. The independent association between low baseline vitamin D status and delayed sputum smear conversion remained strong after adjustment for sex, radiological extent of disease and drug sensitivity (adjusted Hazard Ratio [aHR] $4.51,95 \%$ CI 1.91 to $10.70, P=0.001$ ). The independent association between presence of MDR TB and delayed sputum smear conversion was also replicated in this subgroup analysis (aHR 3.59, $95 \%$ CI 1.77 to $7.30, P<0.001$ ). The findings of this sub-group analysis suggest that the association between low vitamin D status and delayed sputum smear conversion seen in the study population as a whole are likely to be independent of the effects of MDR TB on this outcome.

\section{Influence of gene-environment interaction on time to sputum conversion}

We have previously reported that polymorphisms in the vitamin $D$ receptor modify the effect of vitamin $D$ supplementation on time to sputum culture conversion [17]. We were therefore interested to determine whether the strength of association between profound vitamin D deficiency and delayed sputum smear conversion differed according to genetic variation in VDR, DBP and CYP2R1. Results of the pertinent interaction analyses are presented in Table 4. Prior to correction for multiple analyses, statistically significant associations between profound vitamin D deficiency and delayed sputum smear conversion were found in 
Table 1 Demographic and clinical characteristics of study participants at baseline $(n=260)$

\begin{tabular}{|c|c|c|}
\hline Age & Mean age, years (s.d.) & $.31 .6(10.5)$ \\
\hline & Age range, years & 14 to 55 \\
\hline \multirow[t]{2}{*}{ Sex } & Male, N (\%) & 120 (46\%) \\
\hline & Female, N (\%) & 140 (54 \%) \\
\hline \multirow[t]{2}{*}{ Socioeconomic status ${ }^{a}$} & Lower, N (\%) & $177(68 \%)$ \\
\hline & Higher, N (\%) & $83(32 \%)$ \\
\hline \multirow[t]{2}{*}{ Month of recruitment } & April - September, N (\%) & 137 (53\%) \\
\hline & October - March, N (\%) & $123(47 \%)$ \\
\hline \multirow[t]{3}{*}{ Sensitivity profile } & Fully-sensitive & $56(22 \%)$ \\
\hline & Multidrug-resistant & $16(6 \%)$ \\
\hline & Undetermined & 188 (72\%) \\
\hline \multirow[t]{2}{*}{ Extent of disease } & Unilateral & 144 (55 \%) \\
\hline & Bilateral & 116 (45\%) \\
\hline \multirow[t]{2}{*}{ Sputum smear } & 1-99 AFB per $100 \mathrm{HPF}$ & 177 (68 \%) \\
\hline & $\geq 100$ AFB per $100 \mathrm{HPF}$ & $83(32 \%)$ \\
\hline \multirow{5}{*}{$\begin{array}{l}\text { Serum } \\
\text { 25-hydroxyvitamin D } \\
\text { concentration }\end{array}$} & Median, nmol/L (IQR) & 23.3 (16.0 to 34.0$)$ \\
\hline & $<25 \mathrm{nmol} / \mathrm{L}, \mathrm{N}(\%)$ & 140 (54 \%) \\
\hline & 25.0 to $49.9 \mathrm{nmol} / \mathrm{L}, \mathrm{N}(\%)$ & $97(37 \%)$ \\
\hline & 50.0 to $74.9 \mathrm{nmol} / \mathrm{L}, \mathrm{N}(\%)$ & 17 (7 \%) \\
\hline & $\geq 75.0 \mathrm{nmol} / \mathrm{L}, \mathrm{N}(\%)$ & $6(2 \%)$ \\
\hline
\end{tabular}

AFB acid-fast bacilli, HPF high-power microscopy fields

a Lower socioeconomic status indicated by patient being in receipt of financial aid for hospital costs

patients with the GG genotype of rs2228570,VDR (adjusted HR 6.53, $95 \%$ CI 3.99 to $10.66, P<0.001$ ) and in those with the GA genotype (adjusted HR 3.02, $95 \%$ CI 1.82 to $5.01, P<0.001$ ) but not in those with the AA genotype (adjusted HR 4.58, $95 \%$ CI 0.56 to $37.25, P=0.16$; $\mathrm{P}$ for interaction $=0.03$ ). However, this interaction did not attain statistical significance after correction for multiple analyses. $\mathrm{P}$ values for the interaction terms for all other genotypes were $>0.05$.

\section{Discussion}

To our knowledge, this is the first study to investigate potential interactions between vitamin D status and polymorphisms in the vitamin D pathway on the response to antituberculous therapy. We report that profound vitamin $\mathrm{D}$ deficiency is highly prevalent among newly-diagnosed TB patients in Pakistan, and that it is strongly and independently associated with markedly delayed sputum smear conversion. By contrast, polymorphisms in genes encoding VDR, DBP and CYP2R1 did not influence either vitamin D status or response to antituberculous therapy as main effects.

The high prevalence of profound vitamin D deficiency that we report among TB patients is striking, especially given that Lahore is located at $31.5^{\circ} \mathrm{N}$, a latitude at which the intensity of ultraviolet radiation should be sufficient to induce cutaneous vitamin $\mathrm{D}$ synthesis yearround [26]. The mean serum $25(\mathrm{OH}) \mathrm{D}$ concentration among patients in our study $(27.3 \mathrm{nmol} / \mathrm{L})$ was lower than that reported in TB patients elsewhere in Punjab province, Pakistan (57.4 nmol/L), [27] and lower than that found among HIV-uninfected adults with active TB in Cape Town (40.5 nmol/L), [28] a sub-tropical setting that is approximately equidistant from the equator (latitude $33.9^{\circ} \mathrm{S}$ ). In both of these case-control studies, vitamin D status was found to be lower among TB patients vs. controls. We hypothesise that low serum $25(\mathrm{OH}) \mathrm{D}$ concentrations may have preceded the onset of active $\mathrm{TB}$, and impaired containment of latent $\mathrm{TB}$ infection, thereby leading to the development of active TB. This hypothesis is supported by findings of longitudinal studies conducted in Pakistan [24] and elsewhere [11] reporting that vitamin $\mathrm{D}$ deficiency in patients at risk of active TB precedes the development of active disease. However, reverse causality or residual confounding cannot be ruled out as explanations for this association, and trials of vitamin $\mathrm{D}$ for $\mathrm{TB}$ prevention are needed in order to determine whether vitamin $\mathrm{D}$ deficiency is a cause, rather than a consequence, of active TB. The coexistence of a high prevalence of vitamin $\mathrm{D}$ deficiency and high incidence of tuberculosis in sub-tropical settings such as Pakistan and South Africa makes them appropriate settings for such trials to be conducted. We also noted that vitamin D deficiency was more prevalent among female vs. male participants in our study; this may be attributable to sex differences in sun exposure and/or dietary vitamin $\mathrm{D}$ intake.

Our finding that vitamin D deficiency associates with impaired response to antituberculous therapy is consistent with reports from other observational studies to investigate this question. Rathored et al. reported an inverse association between serum 25(OH)D concentration and time to sputum smear conversion among 354 patients with multidrug-resistant tuberculosis in New Delhi, India [9]. Sato et al. reported a similar association among 34 patients with drug-sensitive disease in Fukushima, Japan [10]. More recently, Mehta et al. reported that vitamin D insufficiency (serum $25[\mathrm{OH}] \mathrm{D}<75 \mathrm{nmol} / \mathrm{L}$ ) associated with increased risk of treatment relapse in a cohort of $\mathrm{TB}$ patients in Tanzania [11]. The consistency of this association in observational studies contrasts with findings of randomised controlled trials of adjunctive vitamin D to enhance response to antituberculous treatment, which have been more variable, [17, 29-32] although it is worth noting that studies utilising higher doses of vitamin $\mathrm{D}$ have reported acceleration of sputum smear conversion by around 2 weeks $[29,33]-$ similar to the 
Table 2 Determinants of baseline Vitamin D status $(n=260)$

\begin{tabular}{|c|c|c|c|c|c|c|c|c|}
\hline & & & & & Univariate & & Multivariate & \\
\hline & & & N & $\begin{array}{l}25(\mathrm{OH}) \mathrm{D}<25 \mathrm{nmol} / \mathrm{L}, \\
\mathrm{N}(\%)\end{array}$ & OR $(95 \% \mathrm{Cl})$ & $P$ & $\begin{array}{l}\text { Adjusted OR } \\
\left(95 \% \mathrm{Cl}^{\mathrm{a}}\right.\end{array}$ & $P$ \\
\hline Phenotypic & Sex & Male & 120 & $49(41 \%)$ & Ref & & Ref & \\
\hline eristics & & Female & 140 & $91(65 \%)$ & 2.67 (1.62 to 2.45$)$ & $<0.001$ & $2.60(1.50$ to 4.52$)$ & 0.001 \\
\hline & Season of recruitment & Summer & 137 & $66(48 \%)$ & Ref & & Ref & \\
\hline & & Winter & 123 & $74(60 \%)$ & 1.62 (0.99 to 2.65$)$ & 0.053 & 1.75 (1.00 to 3.04$)$ & 0.047 \\
\hline & Socioeconomic status ${ }^{\mathrm{b}}$ & Lower & 177 & $96(54 \%)$ & Ref & & & \\
\hline & & Higher & 83 & $44(53 \%)$ & 0.95 (0.56 to 1.60$)$ & 0.85 & - & - \\
\hline & Extent of disease & Unilateral & 144 & $67(46 \%)$ & Ref & & Ref & \\
\hline & & Bilateral & 116 & $73(63 \%)$ & 1.95 (1.18 to 3.21$)$ & 0.009 & 1.89 (1.49 to 4.52$)$ & 0.025 \\
\hline & Sputum smear & 1-99 AFB per $100 \mathrm{HPF}$ & 106 & $53(50 \%)$ & Ref & & & \\
\hline & & $\geq 100$ AFB per $100 \mathrm{HPF}$ & 154 & $87(56 \%)$ & 0.74 (0.45 to 1.22$)$ & 0.24 & - & - \\
\hline & Age & $<30$ years & 124 & $67(54 \%)$ & Ref & & & \\
\hline & & $\geq 30$ years & 136 & $73(54 \%)$ & 0.98 (0.60 to 1.60$)$ & 0.95 & - & - \\
\hline Genotypic & rs731236, VDR & AA & 83 & $38(46 \%)$ & Ref & 0.14 & & \\
\hline & & $A G$ & 115 & $67(58 \%)$ & 1.65 (0.93 to 2.92) & & - & - \\
\hline & & GG & 27 & $17(63 \%)$ & 2.01 (0.82 to 4.91) & & - & - \\
\hline & rs1544410,VDR & CC & 53 & $23(43 \%)$ & Ref & 0.098 & & \\
\hline & & $C T$ & 128 & $74(58 \%)$ & 1.78 (0.94 to 3.41$)$ & & 1.66 (0.84 to 3.28$)$ & 0.14 \\
\hline & & $\pi$ & 54 & $34(63 \%)$ & 2.21 (1.02 to 4.81$)$ & & 2.23 (0.98 to 5.05$)$ & 0.054 \\
\hline & rs2228570,VDR & GG & 137 & 76 (55 \%) & Ref & 0.96 & & \\
\hline & & GA & 83 & $47(57 \%)$ & 1.04 (0.60 to 1.81$)$ & & - & - \\
\hline & & $\mathrm{AA}$ & 15 & $8(53 \%)$ & 0.92 (0.31 to 2.67) & & - & - \\
\hline & rs2060793, CYP2R1 & GG & 112 & $62(55 \%)$ & Ref & 0.81 & & \\
\hline & & $A G$ & 106 & $62(58 \%)$ & 0.80 (0.22 to 2.94) & & - & - \\
\hline & & $\mathrm{AA}$ & 10 & $5(50 \%)$ & 1.13 (0.66 to 1.94$)$ & & - & - \\
\hline & rs10500804, CYP2R1 & GG & 59 & $34(58 \%)$ & Ref & 0.34 & & \\
\hline & & GT & 120 & $69(58 \%)$ & 0.99 (0.53 to 1.87$)$ & & - & - \\
\hline & & $\pi$ & 52 & $24(46 \%)$ & 0.63 (0.29 to 1.33$)$ & & - & - \\
\hline & rs10766197, CYP2R1 & $\mathrm{AA}$ & 52 & $29(56 \%)$ & Ref & 0.60 & & \\
\hline & & $A G$ & 124 & $72(58 \%)$ & 1.18 (0.57 to 2.11) & & - & - \\
\hline & & GG & 56 & $28(50 \%)$ & 0.84 (0.37 to 1.72$)$ & & - & - \\
\hline & rs7041, DBP & AA & 55 & $34(62 \%)$ & Ref & 0.57 & & \\
\hline & & $A C$ & 106 & $57(54 \%)$ & 0.72 (0.37 to 1.47$)$ & & - & - \\
\hline & & $\mathrm{CC}$ & 71 & $38(54 \%)$ & 0.71 (0.34 to 1.45$)$ & & - & - \\
\hline & rs4588,DBP & GG & 122 & $66(54 \%)$ & Ref & 0.14 & & \\
\hline & & GT & 91 & 49 (54 \%) & 0.99 (0.57 to 1.70$)$ & & - & - \\
\hline & & $\pi$ & 21 & $16(76 \%)$ & 2.71 (0.93 to 7.88 ) & & - & - \\
\hline
\end{tabular}

25(OH)D 25-hydroxyvitamin D, OR odds ratio, Ref referent category, AFB acid-fast bacilli, HPF high-power fields, VDR vitamin D receptor, CYP2R1 vitamin D 25-hydroxylase, $D B P$ vitamin $D$ binding protein

adjusted for sex, season of recruitment, extent of disease and rs1544410 genotype. ${ }^{b}$ lower socioeconomic status indicated by patient being in receipt of financial aid for hospital costs 

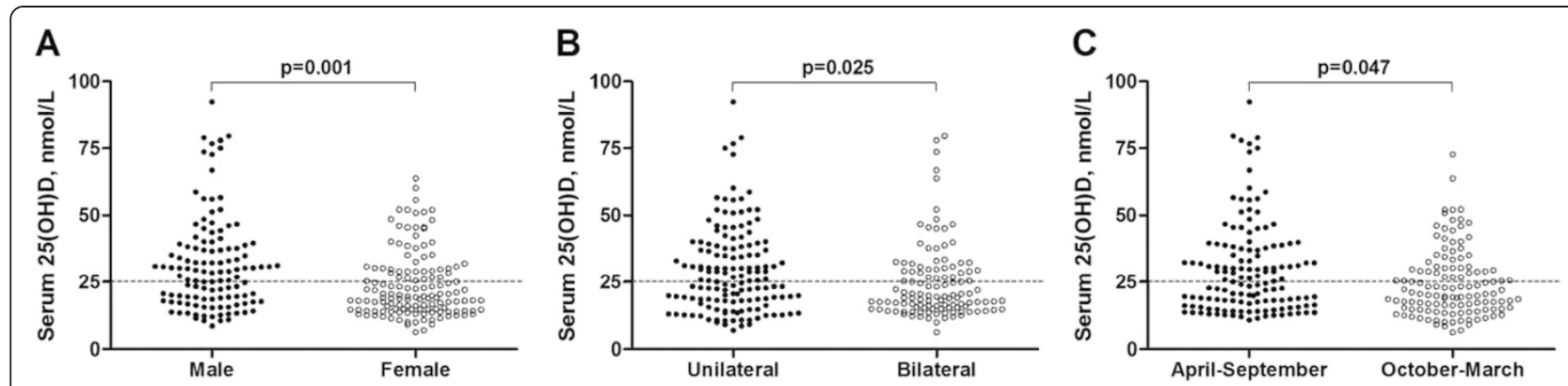

Fig. 2 Serum 25-hydroxyvitamin D concentration for $n=260$ study participants by sex (a), extent of disease (b) and season (c). P values from binary logistic regression adjusted for sex, extent of disease, season of enrolment and Bsm/ vitamin D receptor genotype

15 day difference in time to conversion reported in this study. Potential reasons for the discrepancy between observational studies and clinical trials could be explained by residual confounding in observational studies; inappropriate dosing regimens administered in clinical trials (doses either too small or too widely spaced to cause sustained elevation of serum $25[\mathrm{OH}] \mathrm{D}$ concentration); or insufficient power to detect potentially modest effects in drug-sensitive disease. At least three more trials with generous dosing regimens and/or larger sample sizes are in progress (ClinicalTrials.gov references NCT01657656, NCT01580007 and NCT00507000), and their results are awaited with interest.

Our finding that commonly-studied polymorphisms in the vitamin $\mathrm{D}$ receptor did not influence time to sputum smear conversion contrasts with studies that have variously reported associations with rs2228570 (FokI), [34] rs731236 (TaqI), [13, 34] and rs1544410 (BsmI) [9]. Moreover, we did not find any association between polymorphisms in CYP2R1 or DBP and treatment response. Based on our previous findings suggesting clinically important gene-environment interactions in this context [15-17] we went on to explore the possibility that genetic variation in the vitamin $\mathrm{D}$ pathway might modify the influence of vitamin D status on response to antituberculous treatment : sub-group analyses revealed the persistence of very strong associations between vitamin D deficiency and delayed smear conversion across genotypic sub-groups. Overall, our results suggest that the strong phenotypic influence of profound vitamin D deficiency appears to outweigh any more subtle effect of genotypic variation in the vitamin $\mathrm{D}$ pathway on response to antituberculous therapy.

Our study has several strengths: our investigation of the influence of gene-environment interactions in the vitamin $\mathrm{D}$ pathway on response to antituberculous therapy is novel, as is our investigation of polymorphisms in CYP2R1 and DBP. Loss to follow-up was low $(<5 \%)$ and antituberculous treatment was directly observed. Moreover, phenotypic and genotypic data were available to

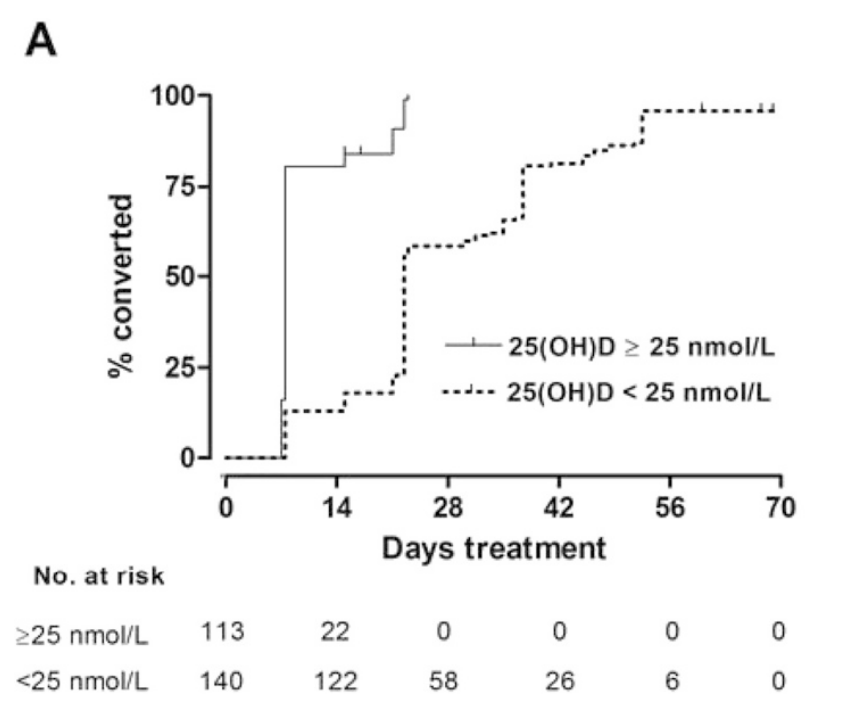

B

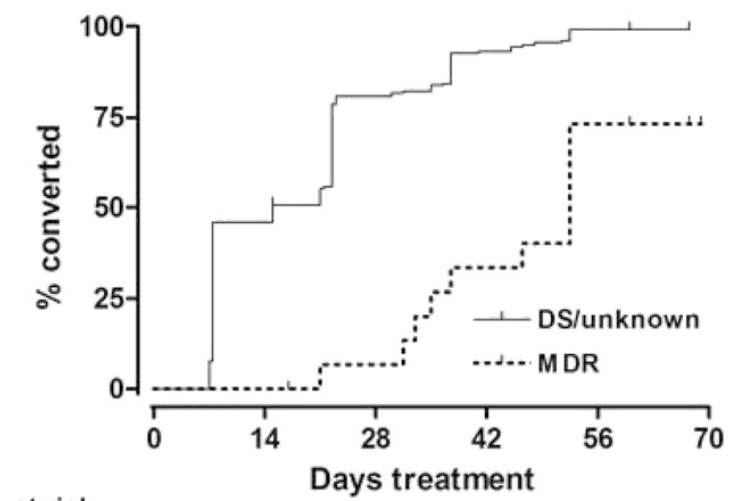

No. at risk

$\begin{array}{rcccccc}\text { DS/unknown } & 237 & 128 & 44 & 16 & 2 & 0 \\ \text { MDR } & 16 & 16 & 14 & 10 & 4 & 0\end{array}$

Fig. 3 Time to sputum smear conversion by baseline vitamin D status (a) and drug sensitivity of $M$. tuberculosis isolate (b). Numbers of patients with positive sputum smear remaining in follow-up (number at risk) at 0,14, 28, 42, 56 and 70 days are shown 
Table 3 Determinants of time to sputum smear conversion $(n=260)$

\begin{tabular}{|c|c|c|c|c|c|c|c|c|}
\hline & & & & & Univariate analys & & Multivariate ana & \\
\hline & & & N & $\begin{array}{l}\text { Median TTSC, } \\
\text { days (IQR) }\end{array}$ & $\mathrm{HR}(95 \% \mathrm{Cl})$ & $P$ & $\begin{array}{l}\text { Adjusted } \\
\text { HR }(95 \% \mathrm{Cl})^{\mathrm{a}}\end{array}$ & $P$ \\
\hline Phenotypic & Sex & Male & 120 & $7.5(7.5-22.5)$ & $1.47(1.11-1.80)$ & 0.01 & $1.16(0.91-1.51)$ & 0.26 \\
\hline & & Female & 140 & $22.5(7.5-35)$ & Ref & - & Ref & - \\
\hline & Socioeconomic status ${ }^{b}$ & Lower & 177 & $21(7.5-30)$ & $0.96(0.73-1.23)$ & 0.68 & - & - \\
\hline & & Higher & 83 & $21(7.5-22.5)$ & Ref & - & - & - \\
\hline & Extent of disease & Unilateral & 144 & $7.5(7.5-22.5)$ & $1.38(1.07-1.78)$ & 0.01 & $1.21(0.85-1.55)$ & 0.23 \\
\hline & & Bilateral & 116 & $22.5(7.5-36.5)$ & Ref & - & Ref & - \\
\hline & Sputum smear & 1-99 AFB per $100 \mathrm{HPF}$ & 106 & $7.5(7.5-22.5)$ & $0.80(0.6-1.01)$ & 0.60 & - & - \\
\hline & & $\geq 100$ AFB per $100 \mathrm{HPF}$ & 154 & $22.5(7.5-23)$ & Ref & - & - & - \\
\hline & Age & $<30$ years & 124 & $21(7.5-22.5)$ & $1.14(0.91-1.50)$ & 0.33 & - & - \\
\hline & & $\geq 30$ years & 136 & $22(7.5-37.5)$ & Ref & - & - & - \\
\hline & $25(\mathrm{OH}) \mathrm{D}$ & $<25 \mathrm{nmol} / \mathrm{l}$ & 140 & $22.5(22.5-37.5)$ & $4.93(3.55-6.86)$ & $<0.001$ & $4.36(3.25-6.65)$ & $<0.001$ \\
\hline & & $\geq 25 \mathrm{nmol} / \mathrm{l}$ & 120 & $7.5(7.5-7.5)$ & Ref & - & Ref & - \\
\hline & Drug sensitivity & Fully-sensitive / unknown & 244 & $15(7.5-22.5)$ & Ref & - & Ref & - \\
\hline & & Multidrug-resistant & 16 & 52.5 (Undefined-35) & $3.92(2.12-7.24)$ & $<0.001$ & $3.35(1.71-6.54)$ & $<0.001$ \\
\hline Genotypic & rs731236, VDR & $\mathrm{AA}$ & 84 & $7.5(7.5-22.5)$ & $0.87(0.71-1.06)$ & 0.16 & - & - \\
\hline & & $A G$ & 117 & $21(7.5-30)$ & & & & \\
\hline & & GG & 29 & $22.5(7.5-37.5)$ & & & & \\
\hline & rs1544410,VDR & CC & 53 & $7.5(7.5-22.5)$ & $0.89(0.73-1.08)$ & 0.26 & - & - \\
\hline & & $\mathrm{CT}$ & 128 & $21(7.5-35)$ & & & & \\
\hline & & $\pi$ & 54 & $21.5(7.5-23)$ & & & & \\
\hline & rs2228570,VDR & GG & 138 & $15(7.5-23)$ & $1.04(0.84-1.28)$ & 0.70 & - & - \\
\hline & & GA & 83 & $22.5(7.5-22.5)$ & & & & \\
\hline & & $\mathrm{AA}$ & 15 & $7.5(7.5-22.5)$ & & & & \\
\hline & rs2060793,CYP2R1 & $\mathrm{AA}$ & 10 & $21(7.5-22.5)$ & $0.88(0.69-1.11)$ & 0.28 & - & - \\
\hline & & $A G$ & 106 & $21(7.5-23)$ & & & & \\
\hline & & GG & 112 & $21(7.5-23)$ & & & & \\
\hline & rs10500804,CYP2R1 & GG & 59 & $15(7.5-22.5)$ & $1.12(0.92-1.38)$ & 0.24 & - & - \\
\hline & & GT & 120 & $22.5(7.5-35)$ & & & & \\
\hline & & $\pi$ & 52 & $7.5(7.5-22.5)$ & & & & \\
\hline & rs10766197,CYP2R1 & $\mathrm{AA}$ & 52 & $15(7.5-22.5)$ & $1.13(0.92-1.38)$ & 0.24 & - & - \\
\hline & & $A G$ & 124 & $22.5(7.5-35)$ & & & & \\
\hline & & GG & 56 & $15(7.5-22.5)$ & & & & \\
\hline & rs7041,DBP & $\mathrm{AA}$ & 55 & $22.5(7.5-22.5)$ & $1.0(0.83-1.21)$ & 0.94 & - & - \\
\hline & & $A C$ & 106 & $15(7.5-22.5)$ & & & & \\
\hline & & CC & 71 & $7.5(7.5-23)$ & & & & \\
\hline & rs4588,DBP & GG & 122 & $21(7.5-23)$ & $1.01(0.82-1.23)$ & 0.90 & - & - \\
\hline & & GT & 91 & $15(7.5-22.5)$ & & & & \\
\hline & & $\pi$ & 21 & $22.5(15-22.5)$ & & & & \\
\hline
\end{tabular}

TISC time to sputum smear conversion, IQR interquartile range, HR hazard ratio, Ref referent category, AFB acid-fast bacilli, HPF high-power microscopy fields, 25(OH)D 25-hydroxyvitamin D, VDR vitamin D receptor, CYP2R1 vitamin D 25-hydroxylase, DBP vitamin D binding protein

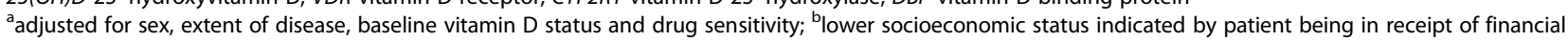
aid for hospital costs 
Table 4 Influence of vitamin D status on time to sputum smear conversion by genetic sub-groups

\begin{tabular}{|c|c|c|c|c|c|c|}
\hline SNP, Gene & Genotype & $\mathrm{N}$ & $\begin{array}{l}\text { Adjusted HR for } 25(\mathrm{OH}) \mathrm{D}<25 \\
\text { vs. } \geq 25 \mathrm{nmol} / \mathrm{L}(95 \% \mathrm{Cl})^{\mathrm{a}}\end{array}$ & $P$ & $\mathrm{HR}$, interaction term $(95 \% \mathrm{Cl})$ & $\mathrm{P}_{\text {interaction }}^{\mathrm{b}}$ \\
\hline \multirow[t]{3}{*}{ rs731236, VDR } & AA & 84 & $5.87(3.20-10.76)$ & $<0.001$ & $0.84(0.56-1.24)$ & 0.37 \\
\hline & $A G$ & 117 & $4.27(2.65-6.86)$ & $<0.001$ & & \\
\hline & GG & 29 & $5.53(1.92-15.94)$ & $<0.001$ & & \\
\hline \multirow[t]{3}{*}{ rs1544410,VDR } & CC & 53 & $5.97(2.73-13.04)$ & $<0.001$ & $0.79(0.53-1.17)$ & 0.24 \\
\hline & $C T$ & 128 & $4.45(2.81-7.05)$ & $<0.001$ & & \\
\hline & $\pi$ & 54 & $4.61(2.25-9.43)$ & $<0.001$ & & \\
\hline \multirow[t]{3}{*}{ rs2228570,VDR } & GG & 138 & $6.53(3.99-10.66)$ & $<0.001$ & $0.61(0.38-0.96)$ & 0.03 \\
\hline & GA & 83 & $3.02(1.82-5.01)$ & $<0.001$ & & \\
\hline & AA & 15 & $4.58(0.56-37.25)$ & 0.16 & & \\
\hline \multirow[t]{3}{*}{ rs7041,DBP } & AA & 55 & $4.81(2.49-9.32)$ & $<0.001$ & $1.0(0.69-1.45)$ & 0.98 \\
\hline & $A C$ & 106 & $6.39(3.61-11.30)$ & $<0.001$ & & \\
\hline & CC & 71 & $3.29(1.86-5.83)$ & $<0.001$ & & \\
\hline \multirow[t]{3}{*}{ rs4588,DBP } & GG & 122 & $3.65(2.32-5.75)$ & $<0.001$ & $1.09(0.70-1.68)$ & 0.69 \\
\hline & GT & 91 & $6.46(3.60-11.59)$ & $<0.001$ & & \\
\hline & $\pi$ & 21 & $3.92(3.60-5.78)$ & $<0.001$ & & \\
\hline \multirow[t]{3}{*}{ rs10500804,CYP2R1 } & GG & 59 & $4.46(2.28-8.71)$ & $<0.001$ & $1.06(0.71-1.58)$ & 0.76 \\
\hline & GT & 120 & $4.69(2.89-7.61)$ & $<0.001$ & & \\
\hline & $\pi$ & 52 & $5.38(2.35-12.31)$ & $<0.001$ & & \\
\hline \multirow[t]{3}{*}{ rs2060793,CYP2R1 } & AA & 10 & $4.47(0.81-24.47)$ & 0.084 & $0.86(0.54-1.36)$ & 0.53 \\
\hline & $A G$ & 106 & $6.79(3.86-11.94)$ & $<0.001$ & & \\
\hline & GG & 112 & $4.10(2.52-6.68)$ & $<0.001$ & & \\
\hline \multirow[t]{3}{*}{ rs10766197,CYP2R1 } & AA & 52 & $4.15(2.08-8.29)$ & $<0.001$ & $1.03(0.68-1.54)$ & 0.88 \\
\hline & $A G$ & 124 & $5.12(3.15-8.32)$ & $<0.001$ & & \\
\hline & GG & 56 & $4.82(2.25-10.30)$ & $<0.001$ & & \\
\hline
\end{tabular}

SNP single nucleotide polymorphism, $H R$ hazard ratio, 25(OH)D 25-hydroxyvitamin $D, C l$ confidence interval, VDR vitamin D receptor, CYP2R1 vitamin D 25-hydroxylase, DBP vitamin D binding protein

adjusted for drug sensitivity profile; ${ }^{b}$ none of these were significant using a Benjamini and Hochberg procedure controlling the false discovery rate at $20 \%$

allow us to adjust for potential confounders of the relationship between vitamin D status and treatment response using multivariate analysis.

Our study also has some limitations. First, it was observational in nature; accordingly, residual confounding cannot be excluded as an explanation for the association between vitamin D deficiency and delayed smear conversion that we report. Second, information on time to sputum culture clearance was not available to us: culture is both more sensitive and more specific than microscopy for the detection of viable mycobacteria in sputum, and sputum culture conversion is the only outcome of intensive-phase treatment that has been shown to correlate with 2-year risk of relapse [35]. Third, drug sensitivity testing was not performed for all $M$. tuberculosis isolates, due to limited availability of resources. However, sensitivity testing was performed in patients at risk of drug-resistance (i.e. those who were sputumsmear positive after 2 weeks of intensive-phase anti-TB treatment, and who had either been previously treated for tuberculosis or who were known to have had contact with patients with confirmed MDR-TB). These criteria are used in day-to-day clinical practice at Gulab Devi Chest Hospital, and have proven to be sensitive for the identification of patients with drug-resistant tuberculosis: thus, there is a rationale for assuming that patients who did not fulfil these criteria are likely to have drug-sensitive disease.

\section{Conclusion}

In conclusion, we report that profound vitamin D deficiency is highly prevalent among pulmonary TB patients in Lahore, Pakistan, and that this associates with markedly delayed sputum smear conversion in a genotypeindependent manner. Our study adds to the growing body of literature pointing to inadequate vitamin $\mathrm{D}$ status as a correctable risk factor for delayed response to antituberculous therapy. 


\section{Competing interests}

The authors declare that they have no competing interests.

\section{Authors' contributions}

$\mathrm{KJ}, \mathrm{AR}$, TS and ARM contributed to study design; $\mathrm{KJ}$ and TS carried out main experimental work and sampling and follow up of patients; KJ, DAJ and KW carried out genotyping; $\mathrm{KJ}$ and ARM performed statistical analysis; KJ wrote the first draft of this manuscript, with additional input from ARM; all authors read, commented on and approved the final manuscript.

\section{Acknowledgements}

This study was supported by Higher Education Commission of Pakistan grant number BM7-139. The International Research Support Initiative Program of the Higher Education Commission of Pakistan provided funding for travel and lodging (IRSIP 24 BMS 29). We thank the clinical staff of the Gulab Devi Chest Hospital, for their invaluable assistance with patient recruitment, sampling and follow-up.

\section{Author details}

${ }^{1}$ Department of Microbiology and Molecular Genetics, University of the Punjab, Quaid-e-Azam Campus, PO Box No 54590, Lahore 54000, Pakistan. ${ }^{2}$ Centre for Primary Care and Public Health, Barts and The London School of Medicine and Dentistry, Queen Mary University of London, London E1 2AB, UK. ${ }^{3}$ Gulab Devi Chest Hospital, Lahore 54000, Pakistan. ${ }^{4}$ Genome Centre, Barts and The London School of Medicine and Dentistry, Queen Mary University of London, London EC1M 6BQ, UK.

\section{Received: 22 October 2014 Accepted: 10 July 2015 \\ Published online: 21 July 2015}

\section{References}

1. WHO. Global Tuberculosis Report. Geneva: WHO Press; 2013.

2. Martineau AR. Old wine in new bottles: vitamin $D$ in the treatment and prevention of tuberculosis. Proc Nutr Soc. 2012;71(1):84-9.

3. Martineau AR, Honecker FU, Wilkinson RJ, Griffiths CJ. Vitamin D in the treatment of pulmonary tuberculosis. J Steroid Biochem Mol Biol. 2007:103:793-8.

4. Rockett KA, Brookes R, Udalova I, Vidal V, Hill AV, Kwiatkowski D. 1,25-Dihydroxyvitamin D3 induces nitric oxide synthase and suppresses growth of Mycobacterium tuberculosis in a human macrophage-like cell line. Infect Immun. 1998;66(11):5314-21.

5. Sly LM, Lopez M, Nauseef WM, Reiner NE. 1alpha,25-Dihydroxyvitamin D3-induced monocyte antimycobacterial activity is regulated by phosphatidylinositol 3-kinase and mediated by the NADPH-dependent phagocyte oxidase. J Biol Chem. 2001;276(38):35482-93.

6. Liu PT, Stenger S, Li H, Wenzel L, Tan BH, Krutzik SR, et al. Toll-like receptor triggering of a vitamin D-mediated human antimicrobial response. Science. 2006:311(5768):1770-3.

7. Martineau AR, Wilkinson KA, Newton SM, Floto RA, Norman AW, Skolimowska K, et al. IFN-g- and TNF-Independent Vitamin D-Inducible Human Suppression of Mycobacteria: The Role of Cathelicidin LL-37. J Immunol. 2007;178(11):7190-8.

8. Yuk JM, Shin DM, Lee HM, Yang CS, Jin HS, Kim KK, et al. Vitamin D3 induces autophagy in human monocytes/macrophages via cathelicidin. Cell Host Microbe. 2009;6(3):231-43.

9. Rathored J, Sharma SK, Singh B, Banavaliker JN, Sreenivas V, Srivastava AK, et al. Risk and outcome of multidrug-resistant tuberculosis: vitamin D receptor polymorphisms and serum 25(OH)D. Int J Tuberc Lung Dis. 2012;16(11):1522-8.

10. Sato S, Tanino Y, Saito J, Nikaido T, Inokoshi Y, Fukuhara A, et al. Relationship between 25-hydroxyvitamin D levels and treatment course of pulmonary tuberculosis. Respiratory investigation. 2012;50(2):40-5.

11. Mehta S, Mugusi FM, Bosch RJ, Aboud S, Urassa W, Villamor E, et al. Vitamin $D$ status and TB treatment outcomes in adult patients in Tanzania: a cohort study. BMJ open. 2013;3(11):e003703.

12. Roth DE, Soto G, Arenas F, Bautista CT, Ortiz J, Rodriguez R, et al. Association between vitamin $D$ receptor gene polymorphisms and response to treatment of pulmonary tuberculosis. J Infect Dis. 2004;190(5):920-7.

13. Babb C, van der Merwe L, Beyers N, Pheiffer C, Walzl G, Duncan K, et al. Vitamin D receptor gene polymorphisms and sputum conversion time in pulmonary tuberculosis patients. Tuberculosis (Edinb). 2007;87(4):295-302.
14. Wang TJ, Zhang F, Richards JB, Kestenbaum B, van Meurs JB, Berry D, et al. Common genetic determinants of vitamin $D$ insufficiency: a genome-wide association study. Lancet. 2010;376(9736):180-8.

15. Wilkinson RJ, Llewelyn M, Toossi Z, Patel P, Pasvol G, Lalvani A, et al. Influence of vitamin $D$ deficiency and vitamin $D$ receptor polymorphisms on tuberculosis among Gujarati Asians in west London: a case-control study. Lancet. 2000;355(9204):618-21.

16. Martineau AR, Leandro AC, Anderson ST, Newton SM, Wilkinson KA, Nicol MP, et al. Association between Gc genotype and susceptibility to TB is dependent on vitamin D status. Eur Respir J. 2010;35(5):1106-12.

17. Martineau AR, Timms PM, Bothamley GH, Hanifa Y, Islam K, Claxton AP, et al. High-dose vitamin $D_{3}$ during intensive-phase antimicrobial treatment of pulmonary tuberculosis: a double-blind randomised controlled trial. Lancet. 2011;377(9761):242-50.

18. WHO. Treatment of tuberculosis: guidelines. 4th ed. Geneva: WHO; 2010.

19. Boehme CC, Nabeta P, Hillemann D, Nicol MP, Shenai S, Krapp F, et al. Rapid molecular detection of tuberculosis and rifampin resistance. New Engl J Med. 2010;363(11):1005-15.

20. Ådjers-Koskela K, Katila M-L. Susceptibility testing with the manual mycobacteria growth indicator tube (MGIT) and the MGIT 960 system provides rapid and reliable verification of multidrug-resistant tuberculosis. J Clin Microbiol. 2003;41(3):1235-9.

21. Rapid extraction of high quality DNA from whole blood stored at $4{ }^{\circ} \mathrm{C}$ for long period [http://www.protocol-online.org/prot/Protocols/RapidExtraction-of-High-Quality-DNA-from-Whole-Blood-Stored-at-4-C-for-LongPeriod-4175.html]

22. Martineau AR, MacLaughlin BD, Hooper RL, Barnes NC, Jolliffe DA, Greiller $\mathrm{CL}$, et al. Double-blind randomised placebo-controlled trial of bolus-dose vitamin D3 supplementation in adults with asthma (ViDiAs). Thorax. 2015;70(5):451-7.

23. Lwanga S, Lemeshow S. Sample size determination in health studies: A practical manual. In: Sample size determination in health studies: A practical manual. Geneva: World Health Organization; 1991.

24. Talat N, Perry S, Parsonnet J, Dawood G, Hussain R. Vitamin D deficiency and tuberculosis progression. Emerg Infect Dis. 2010;16(5):853-5.

25. Benjamini Y, Hochberg Y. Controlling the False Discovery Rate - a Practical and Powerful Approach to Multiple Testing. J Roy Stat Soc B Met. 1995;57(1):289-300.

26. Jablonski NG, Chaplin G. The evolution of human skin coloration. J Hum Evol. 2000;39(1):57-106.

27. Iftikhar R, Kamran SM, Qadir A, Haider E, Bin Usman H. Vitamin D deficiency in patients with tuberculosis. Journal of the College of Physicians and Surgeons-Pakistan : JCPSP. 2013;23(10):780-3.

28. Martineau AR, Nhamoyebonde S, Oni T, Rangaka MX, Marais S, Bangani N, et al. Reciprocal seasonal variation in vitamin D status and tuberculosis notifications in Cape Town, South Africa. Proc Natl Acad Sci U S A. 2011;108(47):19013-7.

29. Nursyam EW, Amin Z, Rumende CM. The effect of vitamin D as supplementary treatment in patients with moderately advanced pulmonary tuberculous lesion. Acta Med Indones. 2006;38(1):3-5.

30. Wejse C, Gomes VF, Rabna P, Gustafson P, Aaby P, Lisse IM, et al. Vitamin D as supplementary treatment for tuberculosis: a double-blind, randomized, placebo-controlled trial. Am J Respir Crit Care Med. 2009;179(9):843-50.

31. Salahuddin N, Ali F, Hasan Z, Rao N, Ageel M, Mahmood F. Vitamin D accelerates clinical recovery from tuberculosis: results of the SUCCINCT Study [Supplementary Cholecalciferol in recovery from tuberculosis]. A randomized, placebo-controlled, clinical trial of vitamin D supplementation in patients with pulmonary tuberculosis. BMC Infect Dis. 2013;13:22.

32. Ralph AP, Waramori G, Pontororing GJ, Kenangalem E, Wiguna A, Tjitra E, et al. L-arginine and vitamin $D$ adjunctive therapies in pulmonary tuberculosis: a randomised, double-blind, placebo-controlled trial. PLOS ONE. 2013;8(8), e70032.

33. Coussens AK, Wilkinson RJ, Hanifa Y, Nikolayevskyy V, Elkington PT, Islam K, et al. Vitamin D accelerates resolution of inflammatory responses during tuberculosis treatment. Proc Natl Acad Sci U S A. 2012;109(38):15449-54.

34. Roth $D E$, Jones $A B$, Prosser $C$, Robinson JL, Vohra S. Vitamin D receptor polymorphisms and the risk of acute lower respiratory tract infection in early childhood. J Infect Dis. 2008;197(5):676-80.

35. Mitchison DA. The diagnosis and therapy of tuberculosis during the past 100 years. Am J Respir Crit Care Med. 2005;171(7):699-706. 